\title{
Marketing Medical Marijuana in Florida: A Research Methodology
}

\author{
Robert Pellegrino \\ Tarleton State University
}

\author{
Kimberly Pellegrino \\ Florida Memorial University \\ John Preston Jones \\ Florida Memorial University \\ Max Orezzoli \\ Florida Memorial University
}

\begin{abstract}
On November 8th, 2016 Amendment 2 was approved by 71\% of voters making Florida the 26th state to enact a medical marijuana law. Medical marijuana treatment centers are the only entities in the state that are authorized to cultivate, process, and dispense medical marijuana. Medical marijuana laws vary widely across states, making it extremely difficult to learn from the twenty-five states that have already enacted these laws. Medical marijuana laws also have no history to draw upon that provides evidence of best practices. There remains a scarcity of research conducted in real-time on medical marijuana policies while medical marijuana policy is being developed and implemented at a furious pace (Lamonica, et. al., 2016). Florida also has a specific need to evaluate medical marijuana policies and develop best practices. The fastest growing group of marijuana users in the US are older Americans and Florida has the largest population of older Americans in the country.
\end{abstract}

Keywords: medical marijuana, medical cannabis, cannabis research methodology, marijuana research methodology, cannabis policy, cannabis strategy, new business development, entrepreneurship

\section{INTRODUCTION}

On November 8th, 2016 Amendment 2 was approved by $71 \%$ of voters making Florida the 26th state to enact a medical marijuana law. This created a new section to the Florida constitution entitled "Medical marijuana production, possession and use". Amendment 2 acted as protection from both criminal and civil state prosecution for those qualifying businesses, physicians, caregivers, and patients. The law however does not protect any of these stakeholders from federal prosecutions. Amendment 2 also created the process for certification and regulation of the medical marijuana business, referred to by the State of Florida as Medical Marijuana Treatment Centers (MMTCs). 


\section{MEDICAL MARIJUANA TREATMENT CENTERS}

Medical marijuana treatment centers (MMTC) are the only entities in the state that are authorized to cultivate, process, and dispense medical marijuana. MMTC's are vertically integrated businesses that must be certified by the Office of Medical Marijuana use or OMMU. The certification form DH8013-OMMU04/2018 has three parts. Part two of this form has 16 sections that are used to evaluate MMTC's applications. Each section is scored with a rubric that consists of a maximum of 50 or 100 points. The OMMU then authorizes MMTCs based on their evaluation scores when the application is reviewed. Evaluators are assigned by the OMMU to score each application. The evaluation form and rubric for scoring can be found in form DH8014-OMMU-04/2018. The prospective business must also post a $\$ 5,000,000.00$ Bond referred to as the "Florida Medical Marijuana Performance Bond" using form DH8015-OMMU04/2018. These forms as well as all rules regulations and changes to Florida's Medical Marijuana Law can be found on the OMMU website www.knowthefactsmmj.com. Research questions include: How effective and efficient is this evaluation process? How effective and efficient are the evaluators themselves? Does the process lack rigor or is it too rigorous?

As of March 2021, there were twenty-two licensed MMTC's in the state of Florida. Those MMTC's operate 324 dispensing locations. In October of 2019, there were only 180 dispensing locations - a growth rate of $80 \%$ in a year and a half. Nine of the MMTCs have only recently been authorized and had not reported opening a dispensing location. Each MMTC can operate up to a certain number of dispensaries. The number of dispensaries depends on the specific MMTC. According to the OMMU, two MMTC licenses were for sale at the end of 2019. One license, listed for \$40 million, allows the owner to operate no more than 30 dispensaries. The other license, listed for about $\$ 55$ million, allows the holder to operate up to 35 dispensaries. The largest of the MMTC's is Trulieve. In March of 2021, Trulieve operated 79 dispensaries. The total number of qualified patients who possess an active medical marijuana ID card in Florida has grown tremendously to more than 510,000 as of March 2021. This is nearly a 100\% increase in qualified patients in just over a year. Florida's medical cannabis industry is experiencing unprecedented growth. Unlike many other states, Florida claims a robust list of approved medical conditions that will qualify for medical marijuana treatment. This has helped lead to some of the unprecedented growth (Edwards, 2019).

Josh Decatur, the co-founder of "Trace", a cannabis quality-tracking software startup in Vermont provides a warning to states as they enact medical marijuana policies. "Decatur learned a lot about what can go wrong with regulation when he worked on a cannabis farm in northern California. Policymakers were establishing rules for the industry without input from businesses, and the resulting tracking systems created trust and liability problems" (Allen, 2019). The unprecedented growth in Florida would only exacerbate any trust and liability issues that may be inherent in the system. Research questions include: Do MMTC's, once approved, operate effectively? Are MMTC's the appropriate mechanism for making product recommendations or is there a potential conflict of interest inherent in the structure? How well are MMTC employees trained in product offerings? Are the Florida requirements sufficient for MMTC employees? The Florida law has a background check requirement for employees at an MMTC but any educational training is the sole purview of the MMTC itself. Massachusetts had large problems with a similar structure. "The official task of patient education was left to non-medically trained dispensary entrepreneurs, who, while not required to have any formal training themselves, were nevertheless required to provide educational materials to patients" (Lamonica, et. al., 2016). Many medical marijuana patients in Massachusetts stated that they would have preferred education from their caregiver (Lamonica, et. al., 2016).

\section{MEDICAL MARIJUANA DOCTORS}

Medical doctors must first go through a certification process to prescribe medical marijuana in Florida. This certification process consists of a two-hour video and exam. In a survey of cannabis physicians around the country, Takakuwa, et. al., (2019), reported that more than $75 \%$ of the physicians completed an online medical cannabis $\mathrm{CME}$ and that this is the most common way of obtaining cannabis education. Nearly half 
of the physicians surveyed, however, felt that there was insufficient information available to allow them to work as a cannabis physician, potentially indicating that Florida's certification process by itself has limited effectiveness. Florida law allows for any MD to apply for certification, unlike other states where the healthcare providers prescribing medical marijuana must be separate from "other" healthcare providers and must build their practice with medical marijuana patients as their only source of income (Lamonica, et. al., 2016). This also leads to a situation where many Florida cannabis physicians, because they are not dealing with marijuana patients every day all day, will develop less expertise/experience than other states where physicians are required to deal only with medical marijuana patients. Half of primary care doctors at the Mayo clinic offices were not prepared to answer patients' questions concerning medical marijuana, according to another 2019 survey (Harrar, 2019). Marijuana dispensaries in Massachusetts expressed frustration about the lack of medical marijuana education among most medical establishments. General physicians in Massachusetts spoke derogatively of physicians who certified patients for marijuana use (Lamonica, et. al., 2016).

Takakuwa et al., (2019) also revealed that only one physician (3\%) reported receiving any medical school education in cannabis medicine. Four physicians (12\%) had some cannabis education during their residency. Most physicians indicated that they received cannabis information and education through conferences or peer reviewed research. Physicians felt that they knew more about cannabinoids than terpines and less than half of the physicians provided ratio recommendations (the level of THC in a product) or the chemotype (strain of cannabis) to their patients. Nearly half (46\%) felt that there was insufficient information available to them to work as a specialist in cannabis (Takakuwa, et. al., 2019). Based on the literature, research questions for medical marijuana doctors include: Do the same biases exist in Florida physicians that became apparent in Massachusetts physicians? Do the same deficiencies in knowledge exist in Florida physicians that the literature indicates? Is Florida's current certification process for cannabis physicians effective? Are there any conflicts of interest that could arise from the certifying process? Are MD's more or less informed on current marijuana research and knowledge as a result of this structure? Do medical doctors have the knowledge to make product recommendations?

\section{MEDICAL MARIJUANA PATIENTS}

Patients must be approved by a certified physician for medical marijuana use. Although the doctor writes the prescription, it is the MMTC that makes the recommendation on which products to use. The doctor's prescription is a broad-based order. It is up to the MMTC to determine what specific products to offer and recommend to a medical marijuana patient. It is the MMTC employee that interacts with the patient to choose products. Kramer (2019) indicates some of the key aspects to effectively training MMTC employees: 1) make sure employees understand how to talk to patients without violating HIPAA regulations, 2) teach employees about cannabinoids and terpenes, which are the active ingredients in cannabis and various combinations work differently for different ailments, terpenes can also counteract or enhance cannabinoids 3) review every single product in the store with employees and discuss dosage and usage recommendations for all products, encourage employees to continue studying products. The rubric that is used to approve medical marijuana dispensaries requires a plan for employee training. This training plan requirement includes topics such as patient education and patient confidentiality. However, it appears that how to deliver training and how much training to deliver is left to the MMTC. The training plan requirement is also one of six sections under the Technical Ability: Medical Marijuana Dispensing Rubric. The same rubric also requires a plan for patient education that includes topics such as safe use, legal use, and storage. Again, it appears that how much patient education is done is left to the MMTC. This rubric is worth 50 points in total out of 1,150 points available for approving an MMTC (less than 5\%).

More than 500,000 residents in Florida have gained access to medical marijuana but research indicates that a serious knowledge gap may exist concerning the product itself among consumers of medical marijuana. There is evidence that medical marijuana patients spend more time looking for information about

cannabis than recreational users do, indicating a knowledge gap (Krauss, et. al., 2017). There is also evidence that medical dispensaries advertise health benefits that have not been validated through medical 
research (Krauss, et. al., 2017), (Cavazos-Rehg, et. al., 2018). Dispensaries would likely be financially motivated to increase sales by highlighting medical benefits. Research also indicates that dispensary websites infrequently list the adverse side effects of marijuana usage. A study of 100 randomly selected dispensary websites from 10 states indicated that less than half of the dispensaries warned customers of possible side effects and warnings about contraindications were only included on $18 \%$ of the websites (Cavazos-Rehg, et. al., 2018). Examples of some of the questions new medical cannabis users have include things like: Does it work? Is it Safe? Do all products get you "high"? What products will help the most? How much THC should I use? There are also concerns around the purchase of medical marijuana. These purchases are not covered by the VA, Medicare, Medicaid or private insurance (Harrar, 2019). Research questions should include: Do customers know enough about medical marijuana when they walk into an MMTC? Do customers know enough about medical marijuana when they walk out of an MMTC with the product?

\section{SIGNIFICANCE}

Marijuana's "first recorded use as an intoxicant occurred in 2737 B.C. by the Emperor Shen Nung. In addition to extolling its euphoric effects, he recommended it ffor treating female weakness, gout, rheumatism, malaria, beriberi, constipation and absent-mindedness" (Stern, 2009). Even though the use of marijuana by humans dates back thousands of years, the enacting of policy regarding its use remains a complicated and difficult issue. Due to the lack of heterogeneity among state marijuana laws, this project takes on tremendous significance. Medical marijuana laws have no history to draw upon that provides evidence of best practices. There remains a scarcity of research conducted in real-time on medical marijuana policies while medical marijuana policy is being developed and implemented at a feverish pace (Lamonica, et. al., 2016).

Political ideologies, opposing theories, controversial opinions and relentless media attention impact the formulation of drug policy (Fraser, 2011). The research issue is further complicated by the heterogeneity of medical marijuana laws across states. There is significant diversity in how states regulate medical marijuana. Regulations are also continually shifting as they are challenged and amended (Lamonica, et. al., 2016). "Recent research has called for more careful analysis of the heterogeneity in medical marijuana laws" (Chapman, et. al., 2016). Pakula (2015) concluded that treating all medical marijuana laws the same way across states is misleading. This lack of uniformity creates an environment that is not conducive to coast-to-coast research or to generalizing research done in other states to Florida. That leaves the responsibility for evaluating medical marijuana laws and their resulting policies principally in the hands of each state.

Florida has a particular need for evaluating their medical marijuana policies and developing best practices. The fastest growing group of marijuana users in the country are older Americans. "Among those ages 50 to 64, cannabis use tripled between 2003 and 2014; among those age 65 and older, usage grew tenfold in the same period. Today, use by older Americans is increasing by 10 to 15 percent per year" (Harrar, 2019). The percentage of people over the age of 65 in the state of Florida is $20 \%$, the national average is $16 \%$. Puerto Rico and Maine are the only other areas that have $20 \%$ of their population over the age of 65 but Florida's much larger population creates one of the largest senior citizen group in the country (US Census, 2017). The older American segment is growing in medical marijuana use at a tremendous rate. Americans over 50 that use pain relievers are more than three times as likely to be marijuana users (Lloyd, et. al., 2018). Recent research indicates that "implementation of medical cannabis laws significantly reduces

distributions of opioid prescriptions among Medicaid and Medicare enrollees" (Tilburg, et. al., 2019, p.110). Florida needs to get this right.

\section{BEST PRACTICES IN MEDICAL MARIJUANA RESEARCH DESIGN}

1. Due to the heterogeneity of medical marijuana laws, research into medical marijuana must take place at the state level. "While state/local autonomy with regard to cannabis policy is not 
necessarily negative (alcohol laws vary by state), it is problematic that policy is being developed without much research to suggest what is most effective from a consumer welfare standpoint" (Kees, et. al., 2020, p.79). There is tremendous variance in marketing laws related to cannabis from state to state.

2. Because of the absence of historical data or best practices concerning medical marijuana, research must begin with an exploratory study. Hannah (2019) recommends that researchers leave the ivory tower "literally and figuratively" and reach out to journalists and practitioners and pay attention to the nuances of cannabis policy. Interviews with the three major stakeholders should be conducted. The interviews should take a semi-structured approach. The interviews will be used to determine how Florida Medical Marijuana policy issues are impacting the companies, doctors and patients. There is some research concerning the implementation of medical marijuana in other states. Although not directly relevant to Florida, due to the heterogeneity of laws, some general guidelines can be used to begin the exploratory process. Research indicates that problems in implementation take the form of three broad categories: transparency, communication and education (Lamonica, et. al., 2016). These issues should be addressed first during the structured portion of the interview process. Then the interview should take a more unstructured approach in order to find relevant and unique themes concerning medical marijuana in Florida. These interviews should be recorded and professionally transcribed so that they can be reviewed by a research team for robust analysis. The Delphi technique has a long- standing use in qualitative academic research and can be found in similar research on the topic (Lamonica, et. al., 2016).

3. Interviews with MMTC's should aim to answer the following specific research questions: How effective and efficient is the MMTC evaluation process? How effective and efficient are the evaluators themselves? Is the evaluation process appropriately rigorous? Do MMTC's, once approved, operate effectively? Are MMTC's the appropriate mechanism for making product recommendations? How well are MMTC employees trained in product offerings?

4. Interviews with Medical Marijuana Doctors should aim to answer the following specific research questions: Do Florida physicians have biases against the use of medical marijuana? Do they have enough knowledge to make product recommendations? Is the certifying process effective and efficient? Are there any conflicts of interest in the certifying process? Are MD's more or less informed on current marijuana research as a result of this structure? Are medical doctors knowledgeable enough to make product recommendations and if they are, should they?

5. Interviews with Medical Marijuana patients should aim to answer the following specific research questions: Do customers know enough about medical marijuana when they walk into an MMTC? Do customers know enough about medical marijuana when they walk out of an MMTC with the product?

6. Exploratory semi-structured interviews should lead to the development of standardized measurement instruments that can be distributed and collected electronically for each of the three major stakeholders (MMTC's, doctors, and medical marijuana patients) in the State of Florida. These instruments should be the eventual goal of a research stream. A survey should be developed for each of the three primary stakeholders based on a robust analysis of the interview transcripts. 


\section{REFERENCES}

Allen, A.W. (2019, September 16). Vermont firm wins patent for hemp, CBD supply chain software. VT Digger. Retrieved from https://vtdigger.org/2019/09/16/vermont-firm-wins-patent-for-hemp-cbdsupply-chain-software/

Cavazos-Regh, P., Krauss, M., Cahn, E., Lee, K., Ferguson, E., Rajbhandari, B., . . B Bierut, L. (2018, April 9). Marijuana promotion online: an investigation of dispensary practices. Prevention Science.

Chapman, S.A., Spetz, J., Lin, J., Chan, K., \& Schmidt, L. (2016, May). Capturing Heterogeneity in Medical Marijuana Policies: A Taxonomy of Regulatory Regimes Across the United States. Substance Use \& Misuse, pp. 1-11.

Edwards, D. (2019, December 30). What you need to know about the Florida cannabis market. Investing News.

Fraser, S., \& Moore, D. (2011). Governing through problems: The formulation of policy on amphetamine-type stimulants in Australia. International Journal of Drug Policy, 22, 498-506.

Hannah, A.L. (2019). Developing a mixed-methods research agenda on medical marijuana policy. Sage Research Methods Cases, Sage Publications Ltd., London.

Harrar, S. (2019, September). Medical Marijuana: Your questions and what we know today. AARP Bulletin, 60(7), 10-20.

Kees, J., Fitzgerald, P., Dorsey, J., \& Hill, R. (2019). Evidence-based cannabis policy: A framework to guide marketing and public policy research. Journal of Public Policy and Marketing, 39(1) 7692.

Kramer, J. (2019, December). How to train budtenders in a new market. Cannabis Dispensary Magazine. Retrieved from https://www.cannibisdispensarymag.com/article/training-budtenders-newcannibis-markets/

Krauss, M., Sowles, S., Sehi, A., Spitznagel, E., Berg, C., Bierut, L., \& Cavazos-Rehg, P. (2017). Marijuana advertising exposure among current marijuana users in the US. Drug and Alcohol Dependence, 174, 192-200.

Lamonica, A.K., Boeri, M., \& Anderson, T. (2016, March). Gaps in medical marijuana policy implementation: Real-time perspectives from marijuana dispensary entrepreneurs, health care professionals and medical marijuana patients. Drugs Education, Prevention and Policy, pp. 1-13.

Lloyd, S., \& Striley, C. (2018). Marijuana use among adults 50 years or older in the $21^{\text {st }}$ century. Gerontology and Geriatric Medicine, 4, 1-14.

Office of Medical Marijuana Use (OMMU). (n.d). Retrieved from https;//knowthefactsmmj.com/

Pacula, R.L., Powell, D., Heaton, P., \& Sevigny, E.L. (2015). Assessing the effects of medical marijuana laws on marijuana use: The devil is in the details. Journal of Policy Analysis and Management, 34(1), 7-31.

Stern, R.C., \& DiFonzo, H. (2009). The end of the red queens race: Medical Marijuana in the new century. Quinnipiac Law Review, 27, 673-765.

Takakuwa, K., Mistretta, A., Padzernik, V., \& Sulak, D. (2019). Education, knowledge, and practice characteristics of cannabis physicians: A survey of the Society of Cannabis Clinicians. Cannabis and Cannabinoid Research, $X, \mathrm{X}$.

Tilburg, W., Hodge, J., \& Gourdet, C. (2019). Emerging public health law and policy issues concerning state medical cannabis programs. Journal of Law Medicine and Ethics, 47, 108-111. 